\title{
Stellate Cells Orchestrate Concanavalin A-Induced Acute Liver Damage
}

\author{
Richa Rani, ${ }^{* \dagger \ddagger}$ Ashish Tandon, * Jiang Wang, Sudhir Kumar, ${ }^{* \dagger \ddagger}$ and Chandrashekhar R. Gandhi* ${ }^{* \dagger}$
}

From the Departments of Surgery* and Pathology, ${ }^{\S}$ University of Cincinnati, Cincinnati; the Cincinnati Veterans Administration Medical Center, ${ }^{\dagger}$ Cincinnati; and the Department of Pediatrics, ${ }^{\ddagger}$ Cincinnati Children’s Hospital Medical Center, Cincinnati, Ohio

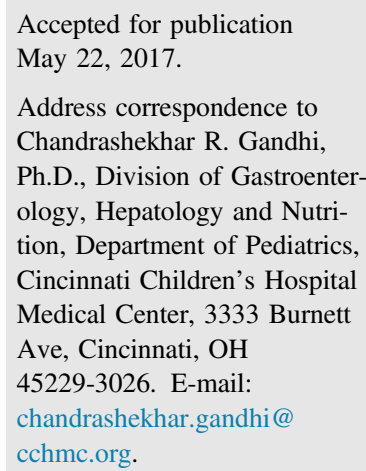

Address correspondence to Chandrashekhar R. Gandhi, Ph.D., Division of Gastroenterology, Hepatology and Nutrition, Department of Pediatrics, Cincinnati Children's Hospital Medical Center, 3333 Burnett Ave, Cincinnati, $\mathrm{OH}$ 45229-3026. E-mail: chandrashekhar.gandhi@ cchmc.org.

\begin{abstract}
Concanavalin A (ConA) causes immune cell-mediated liver damage, but the contribution of resident nonparenchymal cells (NPCs) is also evident. Hepatic stellate cells (HSCs) induce hepatic inflammation and immunological reactions; we therefore investigated their role in ConA-induced liver injury. ConA was administered i.v. to control or HSC-depleted mice; hepatic histopathology and cytokines/chemokines were determined after 6 hours. In vitro, effects of ConA-conditioned HSC medium on hepatocytes were determined. ConA induced inflammation, sinusoidal congestion, and extensive midzonal hepatocyte death in control mice, which were strongly minimized in HSC-depleted mice. CD4 and natural killer T cells and neutrophils were markedly reduced in ConA-treated HSC-depleted mice compared with control mice. The increase in cytokines/chemokines of hepatic injury was much higher in ConA-treated control mice than in HSC-depleted mice. ConA-treated HSCs showed increased expression of interferon$\beta$, tumor necrosis factor- $\alpha$, and $C X C L 1$, induced oxidative stress in hepatocytes, and caused hepatocyte apoptosis. ConA induced nuclear translocation of interferon-regulatory factor-1 (IRF1) in hepatocytes in vivo, and ConA/HSC induced a similar effect in cultured hepatocytes. IRF1-knockout mice were resistant to ConA-induced liver damage, and anti-interferon $\beta$ antibody mitigated ConA/HSC-induced injury. In HSC-NPC co-culture, ConA-induced expression of inflammatory cytokines/chemokines was significantly augmented compared with NPCs alone. HSCs play an essential role in ConA-induced liver injury directly via the interferon- $\beta$ /IRF1 axis, and by modulating properties of NPCs. (Am J Pathol 2017, 187: 2008-2019; http://dx.doi.org/10.1016/j.ajpath.2017.05.015)
\end{abstract}

Acute liver failure is a devastating condition that affects patients with and without prior liver disease. Despite the knowledge of the causal factors, the morbidity and mortality due to acute liver failure of various etiologies continue to be high as current pharmacological treatments are ineffective. $^{1-3}$ Although Kupffer cell $(\mathrm{KC})-$, neutrophil-, monocyte-, and T-cell-mediated inflammatory and immune reactions are implicated as components of the pathogenesis of various types of liver damage, it is evident that the understanding of the intracellular and intercellular mechanisms of acute liver failure is still inadequate.

The perisinusoidal hepatic stellate cells (HSCs) interact with other nonparenchymal cells (NPCs) and infiltrating inflammatory cells, and regulate the survival of hepatocytes. ${ }^{4}$ Endotoxin (lipopolysaccharide)-stimulated HSCs produce mediators, such as tumor necrosis factor (TNF)- $\alpha$, IL-6, interferon (IFN)- $\beta$, and nitric oxide, inhibit DNA synthesis, and induce apoptosis of hepatocytes. ${ }^{5-9}$ The importance of HSCs in hepatocyte survival was confirmed by the finding that their depletion imparts protection from endotoxin- and ischemia/reperfusion (I/R)-induced hepatic injury. ${ }^{10}$ By producing numerous cytokines, chemokines, and molecules of antigen presentation, HSCs influence characteristics of inflammatory cells and cells of the immune system. ${ }^{11-15}$ Such bidirectional interactions between HSCs and inflammatory/immune cells can be critical to liver injury and immunological tolerance.

Concanavalin A (ConA)-induced liver damage in mice is an established model of T-cell-mediated acute liver failure, and although the role of the resident NPCs, such as

Supported by Veterans Administration Merit Review award 1IO1BX001174 (C.R.G.) and NIH grant PO1A1081678 (C.R.G.).

Disclosures: None declared. 
$\mathrm{KCs}$, is also reported, ${ }^{16-18}$ whether and how HSCs regulate the damage is not known. The results of this study (parts of which were presented at the American Association for the Study of Liver Diseases meeting ${ }^{19}$ ) demonstrate strong protection of HSC-depleted mice from ConA-induced injury. In addition to causing apoptosis of hepatocytes by stimulating interferon-regulatory factor-1 (IRF1) signaling via IFN- $\beta$, bidirectional interactions of HSCs with NPCs appear to be critical mechanisms of hepatic damage.

\section{Materials and Methods}

\section{Animals and Treatment}

The protocols were approved by the Institutional Animal Care and Use Committee, according to the NIH guidelines. ${ }^{20}$ Wild-type male C57BL/6 (B6-WT), B6.Cg-Tg(Gfap-Tk) 7.1Mvs/J [B6-glial fibrillary acidic protein (GFAP)-TK-Tg], and B6.129S2-Irf1 ${ }^{\text {tmlMak }} / J$ [IRF1-knockout (KO)] mice were purchased from the Jackson Laboratory (Bar Harbor, ME). Four to eight mice per group were used for the in vivo experiments. HSCs were depleted from B6-GFAP-TK-Tg mice, which express herpes simplex virus thymidine kinase transgene under the GFAP promoter, ${ }^{21}$ as described previously ${ }^{10}$ (Supplemental Figure S1). Briefly, B6-GFAP-TK-Tg mice or B6-WT mice (approximately 25 to $30 \mathrm{~g}$ ) received three carbon tetrachloride $(0.16 \mu \mathrm{L} / \mathrm{g}$ in $50 \mu \mathrm{L}$ peanut oil; i.p. $)$ or peanut oil (control) injections, 3 days apart. Each group was divided into two subgroups, one receiving ganciclovir (GCV; $40 \mu \mathrm{g} / \mathrm{g}$ per day; i.p.) in phosphate-buffered saline (PBS) and the other PBS for 10 days. Other controls included untreated B6-GFAP-TK-Tg and B6-WT mice. Carbon tetrachloride-induced hepatic injury/inflammation causes activation of HSCs that enter the cell cycle, and their elimination occurs only in B6-GFAP-TK-Tg mice because of herpes simplex virus thymidine kinase-induced phosphorylatedGCV incorporation into replicating DNA. Mice were euthanized the day after completion of GCV treatment (when initial carbon tetrachloride-induced injury is completely abated $^{10}$ ), or administered ConA (20 mg/kg; i.v.) (SigmaAldrich, St. Louis, MO). Likewise, IRF1-KO and paired WT mice were subjected to ConA or PBS (control). After 6 hours, mice were anesthetized, blood was drawn, and the liver and other organs were excised and washed in ice-cold PBS; portions were fixed in $10 \%$ buffered formalin or paraformaldehyde, or snap frozen in liquid nitrogen. Other major organs from carbon tetrachloride/GCV-treated mice were fixed to determine injury and GFAP expression.

\section{Isolation and Culture of HSCs, NPCs, and Hepatocytes}

HSCs were isolated from male B6-WT mice (40 to $50 \mathrm{~g}$ ), purified using Nycodenz gradient, and cultured, as described previously. ${ }^{13,14}$ The medium was renewed after overnight culture, and cells were used on day 3 of culture. The remaining NPC population was washed, and placed in culture without or with HSCs (10:1 ratio).

Hepatocytes were prepared from the B6-WT mouse liver (25 to $30 \mathrm{~g}$ ), purified, and cultured, as described previously. ${ }^{6,7}$ The medium was renewed after a 3-hour attachment period, and cells were used after overnight culture.

HSCs were incubated in Dulbecco's modified Eagle's medium containing $5 \%$ fetal bovine serum, without or with $50 \mu \mathrm{g} / \mathrm{mL}$ ConA, up to 8 hours. Sterile-filtered HSCconditioned medium was transferred to hepatocytes. Control hepatocytes were placed in medium preincubated without or with ConA.

\section{Histology and Immunohistochemistry}

Formalin-fixed, paraffin-embedded sections of the liver and other organs were stained with hematoxylin and eosin for histopathological examination.

For immunohistochemistry, sections were deparaffinized with xylene, treated with a series of ethanol concentrations, followed by deionized water, then heated in a microwave in $10 \mathrm{mmol} / \mathrm{L}$ sodium citrate ( $\mathrm{pH}$ 6) containing $0.05 \%$ Tween

Table 1 List of Antibodies Used in IHC, IF, and WB

\begin{tabular}{|c|c|c|c|c|c|}
\hline Antibody & Host & Class & Company (location) & Dilution & Application \\
\hline Neutrophil (NIMP-R14) & Rat & Monoclonal & Abcam (Cambridge, MA) & $1: 50$ & $\mathrm{IHC}$ \\
\hline CD4 & Rat & Monoclonal & Life Technologies Corp. (Carlsbad, CA) & $1: 50$ & IF \\
\hline GFAP & Rabbit & Polyclonal & Dako Cytomation (Hamburg, Germany) & $1: 50$ & IF \\
\hline CK19 & Goat & Polyclonal & Santa Cruz Biotechnology, Inc. (Dallas, TX) & $1: 50$ & IF \\
\hline IFN- $\beta$ & Rabbit & Polyclonal & Abcam & $1: 200$ & IF \\
\hline Desmin & Mice & Monoclonal & Santa Cruz Biotechnology, Inc. & $1: 500$ & IF \\
\hline P-JNK & Rabbit & Monoclonal & Cell Signaling & 1:1000 & WB \\
\hline IRF1 & Rabbit & Monoclonal & Cell Signaling & 1:1000 & WB \\
\hline Histone $\mathrm{H} 3$ & Rabbit & Monoclonal & Cell Signaling & $1: 2000$ & WB \\
\hline$\beta$-Actin & Mouse & Monoclonal & Sigma-Aldrich (St. Louis, M0) & 1:1000 & WB \\
\hline
\end{tabular}

GFAP, glial fibrillary acidic protein; IF, immunofluorescence; IFN, interferon; IHC, immunohistochemistry; IRF1, interferon-regulatory factor-1; JNK, C-Jun-Nterminal kinase; P-JNK, phosphorylated JNK; WB, Western blot. 
20, and blocked with PBS containing $1 \%$ bovine serum albumin, $10 \%$ goat serum, and $0.1 \%$ Triton X-100 for 1 hour. Neutrophils were stained using rat anti-neutrophil antibody $(\mathrm{Ab} ; 1: 50$ in PBS containing $1 \%$ bovine serum albumin, $10 \%$ goat serum, and $0.1 \%$ Triton X-100). Details of antibodies are listed in Table 1. After incubation with horseradish peroxidase-conjugated goat anti-rat Ig (ab97057; 1:400), and treatment with diaminobenzidine substrate (ab64238; Abcam, Cambridge, MA), the sections were counterstained with hematoxylin. For CD4 staining, tissue sections were incubated overnight with anti-CD4 Ab (eBioscience, San Diego, CA) at $4^{\circ} \mathrm{C}$. After incubation with fluorochrome-conjugated Alexa Fluor 488 goat anti-rat $\mathrm{IgG}$ (1:400) (Invitrogen Molecular Probes, Carlsbad, CA), sections were washed with PBS with Tween 20 and mounted with DAPI mounting medium (Vector Lab, Burlingame, $\mathrm{CA}$ ), and images were acquired with a Zeiss fluorescence microscope (Zeiss, Thornwood, NY).

For intracellular IFN- $\beta$, HSCs (day 3 of culture) were incubated in medium containing $1 \mu \mathrm{L} / \mathrm{mL}$ protein transport inhibitor brefeldin A (BD Biosciences, San Diego, CA) with or without $50 \mu \mathrm{g} / \mathrm{mL}$ ConA for 6 hours. The cells were washed with ice-cold PBS and fixed in $2 \%$ paraformaldehyde. After permeabilization and blocking with PBS containing $1 \%$ bovine serum albumin, $10 \%$ goat serum, $0.3 \mathrm{~mol} / \mathrm{L}$ glycine, and $0.1 \%$ Triton $\mathrm{X}-100$, the cells were treated with anti-IFN- $\beta$ and anti-desmin Abs overnight at $4^{\circ} \mathrm{C}$, washed, and incubated in Alexa Fluor 594 anti-rabbit and Alexa Fluor 488 anti-rabbit (1:400) (Invitrogen Molecular Probes), respectively, for 1 hour at room temperature. After incubation with secondary $A b$, and washing with PBS, the cells were mounted with DAPI mounting medium, and imaged using fluorescence microscopy.

\section{Biochemical Analyses}

Apoptosis was determined by a terminal deoxynucleotidyl transferase dUTP nick end labeling (TUNEL) assay kit (Roche Pharmaceuticals, Nutley, NJ), as described. ${ }^{7,9}$ Caspase-3 activity was measured using a fluorometric kit (Sigma-Aldrich). The liver tissue was homogenized in cold lysis buffer $(50 \mathrm{mmol} / \mathrm{L}$ HEPES, $\mathrm{pH} 7.4$, containing 150 $\mathrm{mmol} / \mathrm{L} \mathrm{NaCl}, 20 \mathrm{mmol} / \mathrm{L}$ EDTA, $0.2 \%$ Triton X-100, and protease inhibitor cocktail) and incubated on ice for 10 minutes. The lysate was centrifuged $(13,000 \times g / 15$ minutes $/ 4^{\circ} \mathrm{C}$ ), and the caspase- 3 activity in the supernatant was measured (360-nm excitation and 460-nm emission) in a Synergy 3 Multi-Mode Reader (BioTek Instruments Inc., Winooski, VT). For positive control, liver tissue of mice fed an alcohol-containing Lieber-DeCarli liquid diet was used. . $^{2,23}$

Serum alanine aminotransferase was measured using a VetSpec Kit (Catachem, Inc., Bridgeport, CT). Enzymelinked immunosorbent assay kits were used to measure IFN- $\beta$ (PBL Assay Science, Piscataway, NJ), CXCL1/KC (R\&D Systems Inc., Minneapolis, MN), and TNF- $\alpha$,
CXCL10, and IFN- $\gamma$ (eBioscience, San Diego, CA) in liver lysates or cell culture supernatants.

\section{mRNA Analysis}

RNA was extracted using Trizol Reagent (Life Technology, Carlsbad, CA). RNA $(1.5 \mu \mathrm{g})$ was reverse transcribed into cDNA using a High Capacity cDNA Reverse Transcription kit (Applied Biosystems, Foster City, CA), and quantified via quantitative real-time RT-PCR using primers (Table 2), as described. ${ }^{10} \beta$-Actin expression was used for normalization.

\section{Western Blot Analysis}

Liver or cell lysates were prepared in radioimmunoprecipitation assay buffer (Abcam) containing proteases, and were centrifuged at $10,000 \times g$ for 10 minutes. ${ }^{10}$ The protein concentration in the supernatant was measured. Supernatants (20 $\mu \mathrm{g}$ protein) were subjected to SDS-PAGE, and separated proteins were transferred to a polyvinylidene fluoride membrane. After immunoblotting overnight at $4^{\circ} \mathrm{C}$ with primary Abs (Table 1), washing, and incubation with appropriate secondary Abs, blots were developed using Amersham ECL Select detection reagent (GE Health Care, Buckinghamshire, UK). $\beta$-Actin expression was used as internal control, and ImageJ software version $1.50 \mathrm{i}(\mathrm{NIH}$,

Table 2 Primer Sequences for RT-qPCR

\begin{tabular}{lll}
\hline $\begin{array}{l}\text { Primer } \\
\text { name }\end{array}$ & $\begin{array}{l}\text { Primer } \\
\text { type }\end{array}$ & Sequence \\
\hline$\beta$-Actin & Forward & $5^{\prime}$-AGAGGGAAATCGTGCGTGAC-3' \\
& Reverse & $5^{\prime}$-CAATAGTGATGACCTGGCCGT-3' \\
CK19 & Forward & $5^{\prime}$-CGGACCCTCCCGAGATTACA-3' \\
& Reverse & $5^{\prime}$-TGGAGTTGTCAATGGTGGCA-3' \\
CXCL1 & Forward & $5^{\prime}$-CTGCACCCAAACCGAAGTC-3' \\
& Reverse & $5^{\prime}$-AGCTTCAGGGTCAAGGCAAG-3' \\
CXCL10 & Forward & $5^{\prime}$-GACGGTCCGCTGCAACTG-3' \\
& Reverse & $5^{\prime}$-CTTCCCTATGGCCCTCATTCT-3' \\
GAPDH & Forward & $5^{\prime}$-CATGGCCTTCCGTGTTCCTA-3' \\
& Reverse & $5^{\prime}$-CCTGCTTCACCACCTTCTTGAT-3' \\
GFAP & Forward & $5^{\prime}$-ACCGCATCACCATTCCTGTAC-3' \\
& Reverse & $5^{\prime}$-TTGCCTTCTGACACGGATTT-3' \\
IFN- $\beta$ & Forward & $5^{\prime}$-AGCTCCAAGAAAGGACGAACAT-3' \\
& Reverse & $5^{\prime}$-GCCCTGTAGGTGAGGTTGATCT-3' \\
IFN- $\gamma$ & Forward & $5^{\prime}$-CTCTTCCTCATGGCTGTTTCT-3' \\
& Reverse & $5^{\prime}$-TTCTTCCACATCTATGCCACTT-3' \\
IL-6 & Forward & $5^{\prime}$-CCGGAGAGGAGACTTCACAG-3' \\
& Reverse & $5^{\prime}$-TCCACGATTTCCCAGAGAAC-3' \\
IL-10 & Forward & $5^{\prime}$-CCCTGGGTGAGAAGCTGAAG-3' \\
& Reverse & $5^{\prime}$-CACTGCCTTGCTCTTATTTTCACA-3' \\
IRF1 & Forward & $5^{\prime}$-CAGAGGAAAGAGAGAAAGTCC-3' \\
& Reverse & $5^{\prime}$-CACACGGTGACAGTGCTGG-3' \\
TNF- $\alpha$ & Forward & $5^{\prime}$-CCCAGGTATATGGGCTCATACC-3' \\
& Reverse & $5^{\prime}$-GCCGATTTGCTATCTCATACCAGG-3' \\
\hline
\end{tabular}

GAPDH, glyceraldehyde-3-phosphate dehydrogenase; GFAP, glial fibrillary acidic protein; IFN, interferon; IRF1, interferon-regulatory factor-1; RT-qPCR, quantitative real-time RT-PCR; TNF- $\alpha$, tumor necrosis factor- $\alpha$. 
Bethesda, MD; http://imagej.nih.gov/ij) was used to quantify relative expression.

To assess nuclear translocation of IRF1, nuclear extracts were prepared from the liver tissue or cultured cells using extraction reagents (Pierce-Endogen, Rockford, IL). Nuclear $(15 \mu \mathrm{g})$ proteins were separated by $10 \%$ SDS-PAGE. Western blotting was performed using anti-IRF1 $\mathrm{Ab}$ and secondary anti-rabbit IgG (1:2000). Histone H3 expression was used as an internal control.

\section{Determination of 0xidative Stress}

Hepatocytes were washed with PBS $(3 \times)$ and placed in PBS containing $2^{\prime}, 7^{\prime}$-dichlorofluorescin diacetate $(1 \mu \mathrm{mol} / \mathrm{L}$ in dimethyl sulfoxide; Sigma-Aldrich) for 5 minutes before analysis. $2^{\prime}, 7^{\prime}$-Dichlorofluorescin diacetate is deacetylated by cellular esterase and oxidized by reactive oxygen species to $2^{\prime}, 7^{\prime}$-dichlorofluorescin, which was detected by fluorescence microscopy with maximum excitation and emission spectra at 495 and $529 \mathrm{~nm}$, respectively.

\section{Determination of DNA and Membrane Damage}

Hepatocytes were incubated in culture medium containing $15 \mu \mathrm{mol} / \mathrm{L}$ mitotracker (Cell Signaling, Beverly, MA) for 30 minutes, washed twice with PBS, and fixed in ice-cold methanol at $-20^{\circ} \mathrm{C}$ for 20 minutes. After incubation in blocking buffer ( $3 \%$ bovine serum albumin, $0.1 \%$ Triton $\mathrm{X}-100$, and $5 \%$ donkey serum in PBS), hepatocytes were labeled with anti-8-oxoguanine $\mathrm{Ab}$ (1:400; Abcam) overnight at $4{ }^{\circ} \mathrm{C}$, followed by incubation with rabbit anti-mouse fluorescein isothiocyanate, and DAPI for nuclear labeling.

Membrane damage was quantified by measuring lactate dehydrogenase in the culture supernatant using a lactate dehydrogenase cytotoxicity detection kit (Thermo Fisher, Claremont, CA).

\section{Statistical Analysis}

All data are expressed as means $\pm \mathrm{SD}$. Statistical significance between experimental groups was determined by $t$-test and one-way analysis of variance with Tukey post hoc multiple comparison test using Prism software version 6 (GraphPad Software, Inc., San Diego, CA). $P<0.05$ was considered statistically significant.

\section{Results}

\section{Characteristics of HSC-Depleted Mice}

One of the researchers (J.W.), who was blinded to the samples, performed histopathological examination. As previously reported, ${ }^{10}$ no evidence of injury to any of the major organs was observed at the end of carbon tetrachloride, followed by GCV, treatment of B6-WT or B6-GFAP-TKTg mice (Supplemental Figure S2). Furthermore, GFAP ${ }^{+}$ cells in nonliver organs were unaffected by carbon tetrachloride/GCV treatment of B6-WT or B6-GFAP-TK-Tg mice (Supplemental Figure S3). No detectable GFAP expression was found in the kidneys (data not shown). Evidence indicates that cholangiocytes may be marked by GFAP. ${ }^{24,25}$ Carbon tetrachloride/GCV treatment did not cause injury to the biliary epithelial cells, and there was no residual hepatic injury because of earlier carbon tetrachloride administration ${ }^{10}$ (Supplemental Figure S4A). However, at the end of carbon tetrachloride/GCV treatment, $\mathrm{GFAP}^{+}$ HSCs were eliminated from the B6-GFAP-TK-Tg mice but not from the B6-WT mice (Supplemental Figure S4B) or carbon tetrachloride/PBS-treated B6-GFAP-TK-Tg mice (data not shown). ${ }^{10}$ GFAP expression in cholangiocytes was not altered in WT or GFAP-TK-Tg mice by the HSCdepletion protocol (Supplemental Figure S4B). Thus, it is clear that any changes in the liver because of ConA treatment can be attributed to the presence or absence of HSCs.

\section{HSC-Depleted Mice Are Protected from ConA-Induced Liver Injury}

ConA-induced liver injury was similar in vehicle-treated or carbon tetrachloride-pretreated B6-WT and B6-GFAP-TKTg mice (Supplemental Figure S5), and carbon tetrachloride/GCV-treated B6-WT mice (Figure 1), all of which possessed HSCs. These data indicate that modulation of the hepatic microenvironment because of prior carbon tetrachloride treatment has been restored. Therefore, carbon tetrachloride/GCV-treated B6-WT (HSC-sufficient) and B6-GFAP-TK-Tg (HSC-depleted) mice were used in all of the experiments. Hematoxylin and eosin-stained liver sections showed strong necrotic injury in ConA-treated HSC-sufficient, but not in HSC-depleted, mice (Figure 1A). Histology (Figure 1A) and TUNEL staining (Figure 1B) showed robust death of hepatocytes in ConAtreated HSC-sufficient mice versus scattered low-level TUNEL positivity in HSC-depleted mice. The liver injury in HSC-sufficient mice was accompanied by a strong increase in serum alanine aminotransferase, whereas the increase in HSC-depleted mice was low (Figure 1C). The portal and central venous inflammation was also robust in ConA-treated HSC-sufficient mice but low in HSC-depleted mice (Figure 1D). Also, excessive sinusoidal congestion and large necrotic areas in zone 2 were found in HSC-sufficient mice but not in HSC-depleted mice (Figure 1E).

Hepatic Infiltration/Accumulation of Immune Cells and Neutrophils in ConA-Treated HSC-Sufficient and HSC-Depleted Mice

$\mathrm{CD}^{+} \mathrm{T}$ cells and natural killer $\mathrm{T}$ (NKT) cells have been implicated in ConA-induced liver injury. ${ }^{16,17}$ We found only a small number of $\mathrm{CD}^{+} \mathrm{T}$ cells in the ConA-treated HSC-depleted mice compared with HSC-sufficient mice (Supplemental Figure S6A). Interestingly, hepatic mRNA 


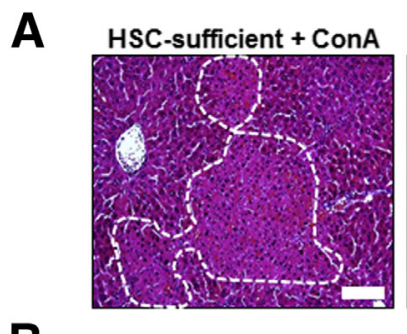

B
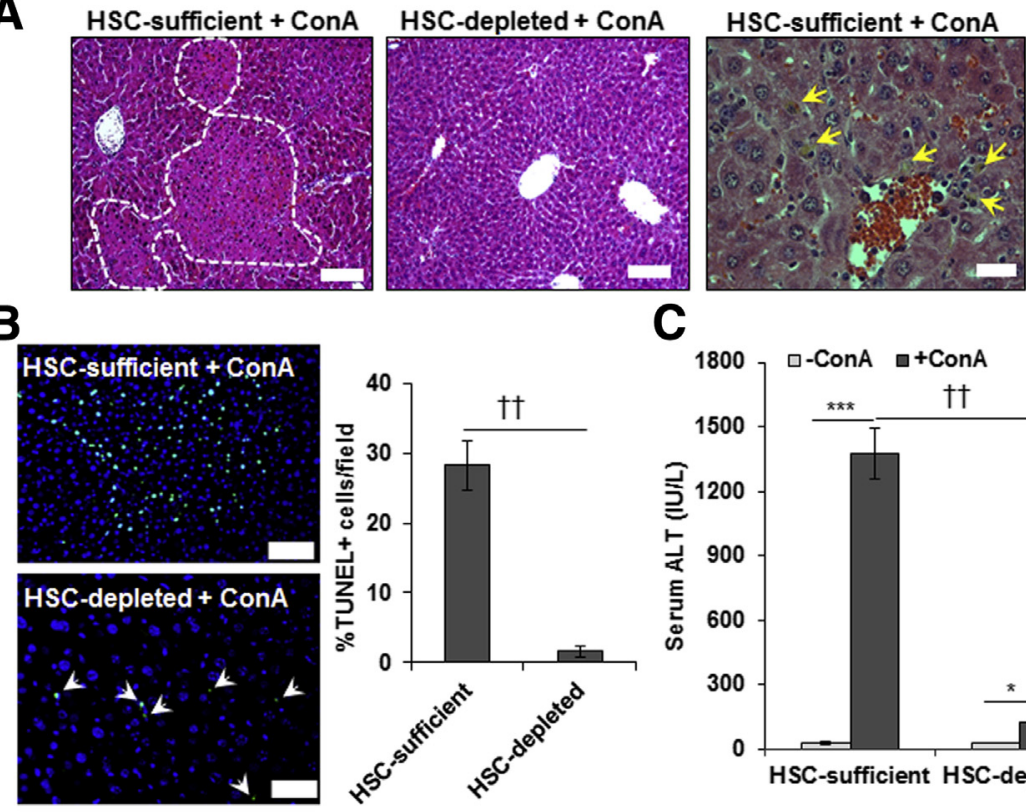

C

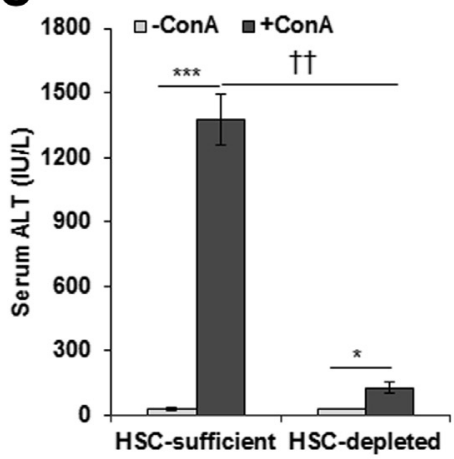

D

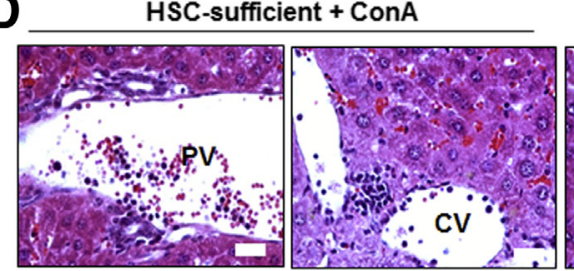

$\mathbf{E}$

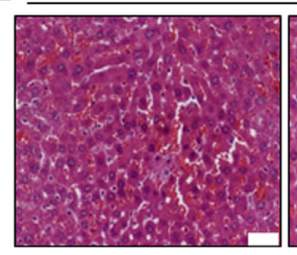

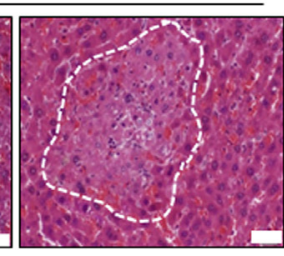

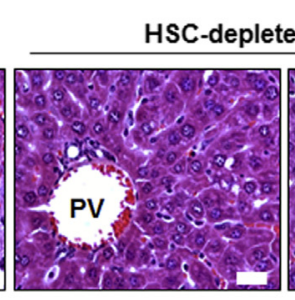

HSC-depleted + ConA

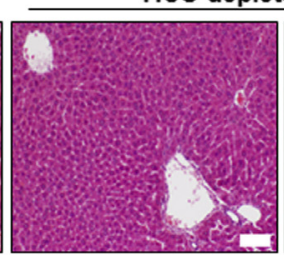

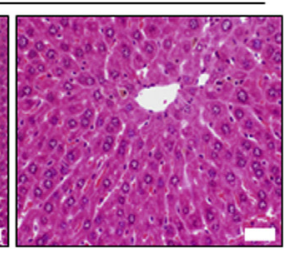

Figure 1 ConA-induced hepatic injury in HSCdepleted mice. HSC-sufficient and HSC-depleted mice were administered $20 \mathrm{mg} / \mathrm{kg}$ ConA, and euthanized 6 hours later. A-C: Representative hematoxylin and eosin (H\&E)- (A) or TUNEL- (B) stained sections, and serum alanine aminotransferase (ALT) levels (C) are shown. Areas marked by dashed lines (left panel) and solid yellow arrowheads (right panel) in $\mathbf{A}$ depict necrotic damage and cell death, respectively. In HSCdepleted mice (middle panel), no defined necrotic areas could be seen. Solid white arrowheads (bottom panel) in B depict TUNEL ${ }^{+}$nuclei. Numerous TUNEL+ cells can be seen in ConAtreated HSC-sufficient mice (top panel). D: H\&Estained liver sections show robust sinusoidal congestion and inflammation in both portal and central areas of HSC-sufficient mice, which are strongly reduced in the $\mathrm{HSC}$-depleted mice. E: Sinusoidal congestion and midzonal necrosis induced by ConA in HSC-sufficient mice is minimal in HSC-depleted mice. Area marked by dashed line depicts necrotic damage. Data are expressed as means \pm SD (B and C). $n=6$ to 8 per group. ${ }^{*} P<0.05,{ }^{* * *} P<0.001$ versus control; ${ }^{\dagger} P<0.01$ versus HSC-depleted mice. Scale bars: $100 \mu \mathrm{m}$ (A, left and middle panels); $20 \mu \mathrm{m}$ (A, right panel, D, and $\mathbf{E}) ; 50 \mu \mathrm{m}(\mathbf{B})$. CV, central vein; $\mathrm{PV}$, portal vein. expression of natural killer group 2D receptor (marker for NKT cells) was similar in untreated HSC-sufficient and HSCdepleted mice (Supplemental Figure S6B), suggesting that the basal NKT cell retention is independent of HSCs. Hepatic natural killer group 2D receptor expression tended to increase in ConA-treated HSC-sufficient mice but decreased in HSCdepleted mice (Supplemental Figure S6B). Neutrophils are also implicated in ConA-mediated liver injury by releasing reactive oxygen species and $\mathrm{TNF}-\alpha$, and by recruiting $\mathrm{CD} 4^{+}$ $\mathrm{T}$ cells. $^{26,27}$ Interestingly, hepatic neutrophil infiltration was significantly reduced in ConA-treated HSC-depleted mice as compared with HSC-sufficient mice, suggesting that HSCs play an important role in neutrophil recruitment (Supplemental Figure S6C).

\section{Altered Expression of Cytokines/Chemokines in ConA-Treated HSC-Depleted Livers}

It is established that HSCs can play a critical role in hepatic inflammation and immune regulation. ${ }^{1-15}$ Because
ConA-induced liver injury is attributed to mediators, such as TNF- $\alpha$ and IFN- $\gamma,{ }^{17,18}$ and considering reduced hepatic levels of inflammatory and immune cells in ConA-treated HSC-depleted compared with HSC-sufficient mice, we examined the hepatic expression of various cytokines and chemokines. Expression of TNF- $\alpha$ and IFN- $\gamma$ mRNA and protein increased strongly in ConA-treated HSC-sufficient but not in HSC-depleted mice (Figure 2, A and B). mRNA expression of IFN- $\beta$, which is also implicated in hepatic injury, ${ }^{28-31}$ increased by 10 -fold in ConA-treated HSC-sufficient mice, but only approximately threefold in HSC-depleted mice (Figure 2A); consistent with these changes, IFN- $\beta$ protein increased strongly in ConA-treated HSC-sufficient and modestly in HSC-depleted mice (Figure 2B). The mRNA expression and protein levels of CXCL1 (neutrophil attractant) and CXCL10 (a T-cell attractant) also increased strongly in ConA-treated HSC-sufficient but not in HSC-depleted mice (Figure 2, $\mathrm{C}$ and D). The data suggest that HSCs are major cells to produce and/or regulate (in other cells) the expression of the 

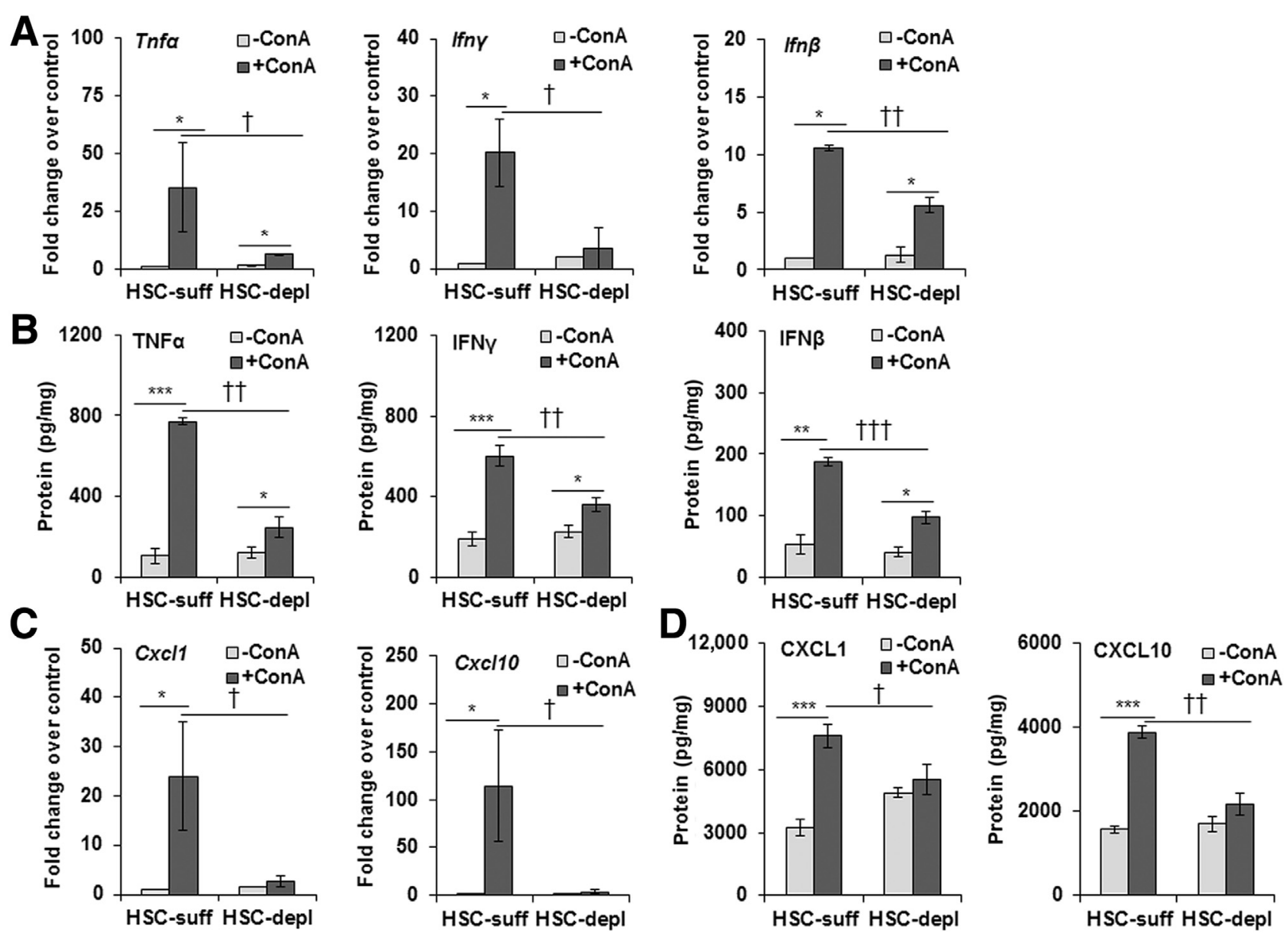

Figure 2 ConA-induced hepatic expression of cytokines and chemokines in HSC-depleted mice. At 6 hours after ConA administration, relative mRNA expression of tumor necrosis factor (TNF)- $\alpha$, interferon (IFN)- $\gamma$, IFN- $\beta$, CXCL1, and CXCL10 in HSC-depleted (HSC-depl) and HSC-sufficient (HSC-suff) mice was determined by quantitative real-time RT-PCR ( $\mathbf{A}$ and $\mathbf{C})$, and corresponding protein levels were measured by enzyme-linked immunosorbent assay (B and $\mathbf{D})$. Data are expressed as means \pm SD. $n=6$ to 8 mice per group. ${ }^{*} P<0.05$, ${ }^{*} P<0.01$, and ${ }^{* *} P<0.001$ versus control; ${ }^{\dagger} P<0.05,{ }^{\dagger \dagger} P<0.01$, and ${ }^{\dagger \dagger \dagger} P<0.001$ versus HSC-depleted mice.

mediators of liver injury, and recruitment of inflammatory/ immune cells. Because NPCs, such as KCs, also produce these cytokines, we determined their ConA-stimulated release in HSC-NPC co-culture. Compared with that in ConA-stimulated NPC monoculture, the expression of the cytokines/chemokines was higher in co-culture with HSCs (Supplemental Figure S7A). That the altered expression of these molecules in HSC-depleted mice was not an effect of the depletion protocol on other cells (such as $\mathrm{KCs}$ ) was ensured by demonstrating no changes in their expression in B6-WT (control) mice treated similarly as compared with the naïve mice (data not shown). ${ }^{10}$

\section{ConA Treatment Increases IRF1 Expression and JNK Activation in HSC-Sufficient But Not in HSC-Depleted Mice}

IRF1 activation (nuclear translocation) causes I/R-induced hepatocyte death, ${ }^{32-34}$ and IRF1-KO mice are resistant to $\mathrm{ConA}^{-35}$ and $\mathrm{I} / \mathrm{R}$-induced ${ }^{36,37}$ liver injury. We observed increased IRF1 expression on ConA treatment of both HSCsufficient and HSC-depleted mice, but the magnitude of increase was much greater in the former (Figure 3A). Furthermore, nuclear translocation of IRF1 increased in ConA-treated HSC-sufficient mice, and this effect was significantly reduced in ConA-treated HSC-depleted mice (Figure 3B). These data suggest that regulation of IRF1 by HSCs may play a role in ConA-induced liver injury.

Sustained or overactivation of c-Jun-N-terminal kinase (JNK) has been shown to cause hepatocyte death during acetaminophen $-{ }^{38}$ and ConA-induced ${ }^{39}$ liver injury. We found that ConA induced activation of JNK in HSC-sufficient but not in HSC-depleted mice (Figure 3C), suggesting that the mediators produced in response to ConA in the hepatic microenvironment in the presence of HSCs, but not in their absence, stimulate JNK activation in hepatocytes.

\section{ConA-Stimulated HSCs Induce 0xidative Stress and Apoptosis of Hepatocytes}

Because HSC-depleted mice are protected from ConAinduced liver injury, we investigated whether ConAstimulated HSCs directly affect viability of hepatocytes. The direct effect of ConA on HSCs was evident from increased 


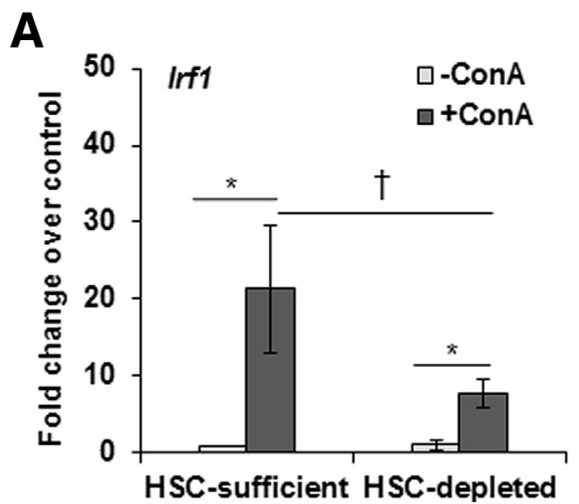

B
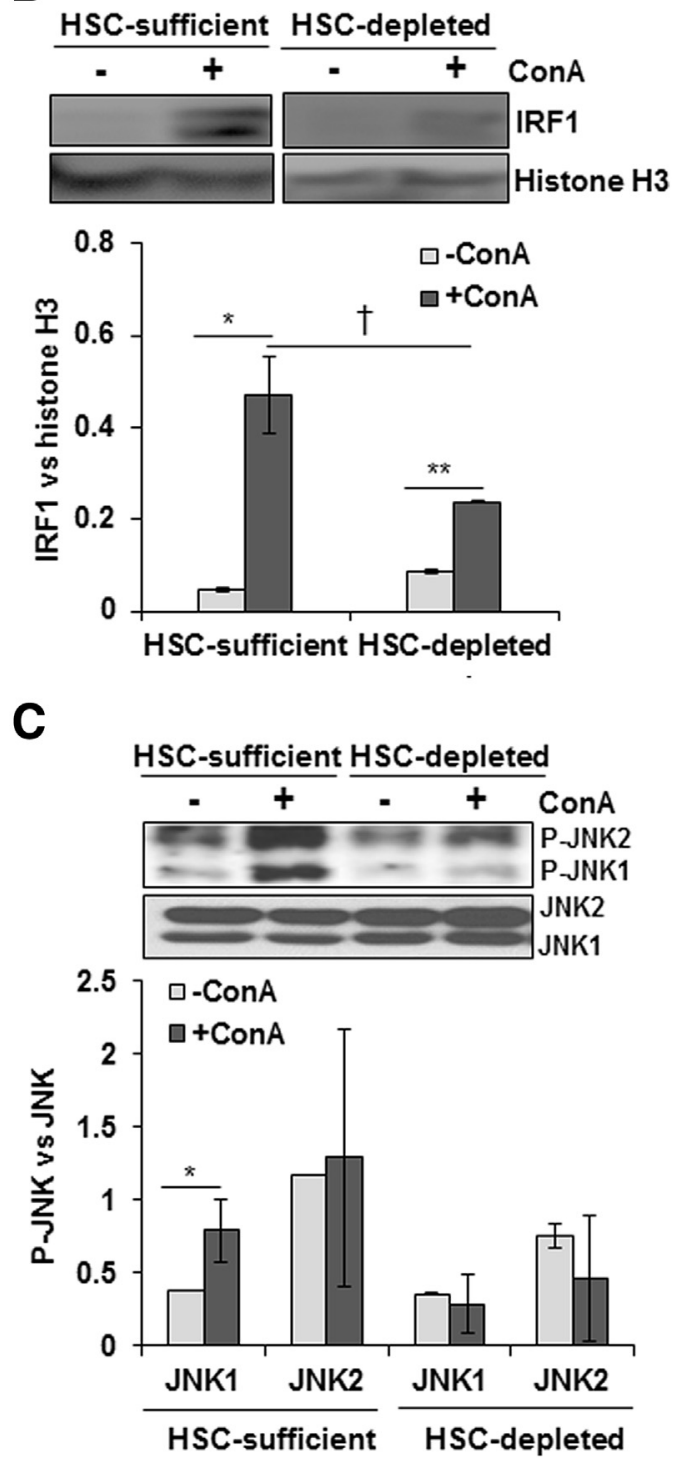

Figure 3 ConA-induced IRF1 expression and JNK activation in HSCdepleted mice. A and B: At 6 hours after ConA administration, HSCdepleted mice show significantly lower hepatic IRF1 mRNA expression (A) and nuclear IRF1 protein levels (B) compared with HSC-sufficient mice. C: JNK activation is reduced in ConA-treated HSC-depleted mice as compared with HSC-sufficient mice. Data are expressed as means \pm SD. $n=4$ to 6 mice per group (C). ${ }^{*} P<0.05,{ }^{* *} P<0.01$ versus control; ${ }^{\dagger} P<0.05$ versus HSCdepleted mice. P-JNK, phosphorylated JNK.
mRNA expression of IRF1, IFN- $\beta$, TNF- $\alpha$, and CXCL1 (Supplemental Figure S7B). 2', 7'-Dichlorofluorescin diacetate analysis showed significantly increased reactive oxygen species production in hepatocytes incubated in medium conditioned by HSCs in presence of ConA for 4 and 8 hours (Figure 4A); medium conditioned in the absence of ConA (Figure 4A) or ConA alone (Figure 4A) did not induce detectable reactive oxygen species generation. An increase in reactive oxygen species was accompanied by rounding of hepatocytes, reduction in cell size with nuclear condensation, and loss of cytoskeletal definition with prominent cellular bleb formation, as determined by phase-contrast microscopy (Figure 4A). TUNEL staining showed a significant increase in apoptotic hepatocytes incubated in ConA-conditioned HSC medium (Figure 4B); HSC-conditioned medium without ConA or ConA alone caused apoptosis of a minor population of hepatocytes. Staining with anti-oxioguanine Ab demonstrated that ConA/HSC-induced apoptosis of hepatocytes was associated with DNA damage (Figure 4C). Furthermore, JNK was activated in ConA/HSC-challenged hepatocytes (Figure 4D). Together, these findings indicate that ConA-stimulated HSCs contribute to hepatocyte injury in vivo. There was no membrane damage to HSCs or hepatocytes incubated in HSC/ConA medium without or with ConA or ConA alone (Supplemental Figure S8, A and B).

\section{Role of IFN- $\beta$, JNK, and IRF1 in ConA/HSC-Induced Hepatocyte Injury}

ConA-treated HSCs showed marked accumulation of intracellular IFN- $\beta$ protein, as illustrated by immunofluorescence staining (Figure 5A) as well as Western blot analysis (Figure 5B). Because ConA/HSC-released IFN- $\beta$ could be a critical mediator of hepatocyte injury and JNK activation is already shown to be an intracellular signaling mechanism of ConA-induced liver cell damage, ${ }^{39}$ the effect of neutralizing IFN- $\beta \mathrm{Ab}$ or JNK inhibitor on ConA/HSC-induced hepatocyte injury was examined. ConA/HSC-induced oxidative stress and hepatocyte damage were attenuated by anti-IFN$\beta \mathrm{Ab}$ as well as JNK inhibitor (Figure $5 \mathrm{C}$ ). Furthermore, both reagents significantly inhibited ConA/HSC-induced caspase-3 cleavage in hepatocytes (Figure 5D).

Next, we determined whether ConA/HSC-released soluble mediators increase nuclear IRF1 in hepatocytes, a mechanism established for I/R damage. ${ }^{32-34}$ Indeed, robust IRF1 nuclear translocation occurred in hepatocytes incubated in medium conditioned by HSCs in the presence of ConA, but not in its absence (Figure 5E).

\section{IRF1-Deficient Mice Are Protected from ConA-Mediated Liver Injury}

Consistent with a previous report, ${ }^{35}$ we found that the ConA-induced liver injury was of lower magnitude in IRF1$\mathrm{KO}$ mice, as determined by histopathology and alanine aminotransferase level (Figure 6A). The hepatic 
A
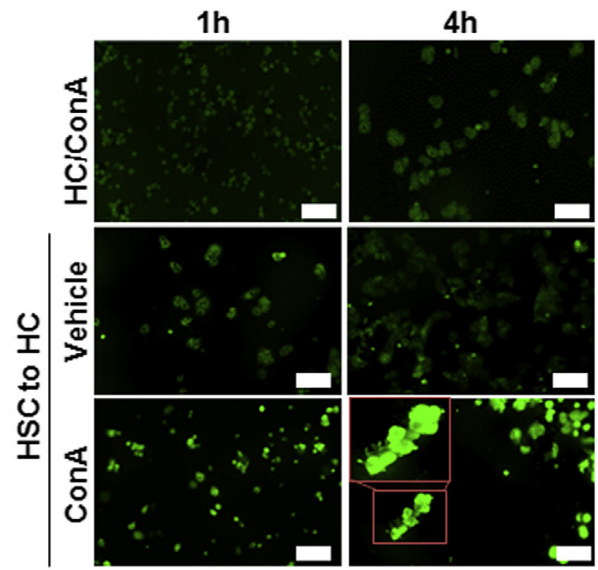

B

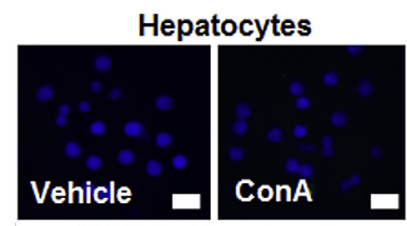

HSC to Hepatocytes

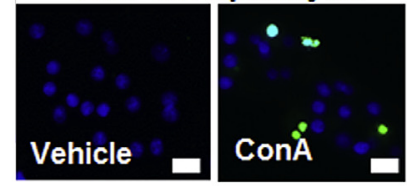

D
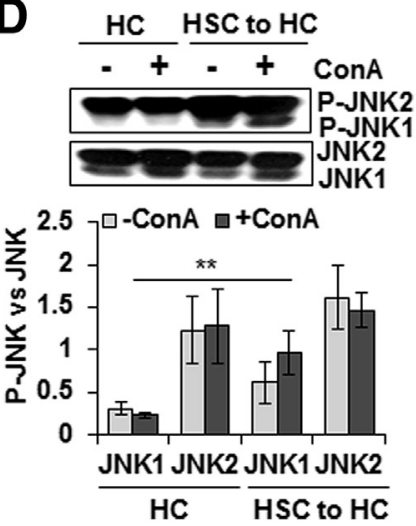

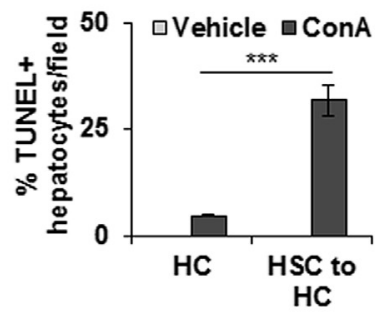

Figure 4 ConA-stimulated HSCs induce oxidative stress, apoptosis, and DNA damage in hepatocytes. A: Hepatocytes (HCs) or HSCs were incubated in medium containing $50 \mu \mathrm{g} / \mathrm{mL}$ ConA for 1,4 , or 8 hours (h). ConA-conditioned HSC medium was then transferred to hepatocytes. After 12 hours, generation of reactive oxygen species in hepatocytes was determined by $2^{\prime}, 7^{\prime}$-dichlorofluorescin diacetate-based staining. Insets in bottom panels of $\mathbf{A}$ are high magnification of indicated areas. Phase-contrast image shows bleb formation in hepatocytes treated with ConA/HSC. B: Hepatocytes were incubated in medium containing $50 \mu \mathrm{g} / \mathrm{mL}$ ConA or medium conditioned by HSCs for 8 hours in absence or presence of ConA. After 12 hours, cells were washed and fixed, and TUNEL staining was performed. C: Hepatocytes were incubated in culture medium containing 15 $\mu \mathrm{mol} / \mathrm{L}$ MitoTracker for 30 minutes, and immunostained with anti-oxioguanine 8 (8-0xoG) Ab (1:400) to detect DNA damage. DAPI was used for nuclear staining. D: Western blot shows phosphorylation of JNK (P-JNK) in hepatocytes, and the bar graph shows activation as quantified via densitometry. All images are representative of three separate experiments. Bar graphs show combined values from three independent experiments. Data are expressed as means \pm SD. ${ }^{*} P<0.05,{ }^{* *} P<0.01$, and ${ }^{* * *} P<0.001$. Scale bars: $100 \mu \mathrm{m}$ (A, left panels, $2^{\prime}, 7^{\prime}$-dichlorofluorescin diacetate-based staining at 1, 4, and 8 hours); $50 \mu \mathrm{m}$ (A, right panel, phase-contrast image, B, and C). Original magnification, $\times 20$ (A, insets). MFI, mean fluorescence intensity. concentrations of IFN- $\beta$, TNF- $\alpha$, IFN- $\gamma$, CXCL1, and CXCL10 were also significantly lower in ConA-treated IRF1-KO than in WT mice (Figure 6B). Furthermore, JNK activation remained negligible in ConA-challenged IRF1-KO mice (Supplemental Figure S9A). Interestingly, unlike in hepatocytes incubated in ConA/HSC medium, ConA did not induce caspase-3 cleavage in WT, HSCdepleted, or IRF1-KO mice, as determined by Western blot analysis and caspase-3 activity assay (Supplemental Figure S9B).

\section{Discussion}

Acute liver failure is a complex phenomenon orchestrated by the direct actions of the injury-causing agents on hepatocytes and/or by mediators produced by the responding
NPCs as well as infiltrating inflammatory or immune cells Although hepatic macrophages KCs, NK cells, and NKT cells as well as monocytes and $\mathrm{CD} 4^{+} \mathrm{T}$ cells have been reported to play roles in both liver damage and protection, there is limited evidence for the contribution of HSCs in these phenomena. Because of their unique location, ability to produce many potent cytokines/chemokines, and interactions with other cells, HSCs can be critically important for liver cell survival. Herein, we found that HSCs are the major cell type to orchestrate ConA-induced liver damage.

Significantly less severe ConA-induced liver pathology was observed in type I and type II NKT cell-deficient $\mathrm{CD} 1 \mathrm{~d}^{-1-}$ mice, or in mice with reduced hepatic NKT cell numbers than wild-type controls. ${ }^{40,41}$ Furthermore, adoptive transfer of hepatic NKT cells to NKT-deficient mice was found to restore ConA-mediated hepatitis. ${ }^{41}$ Our data 


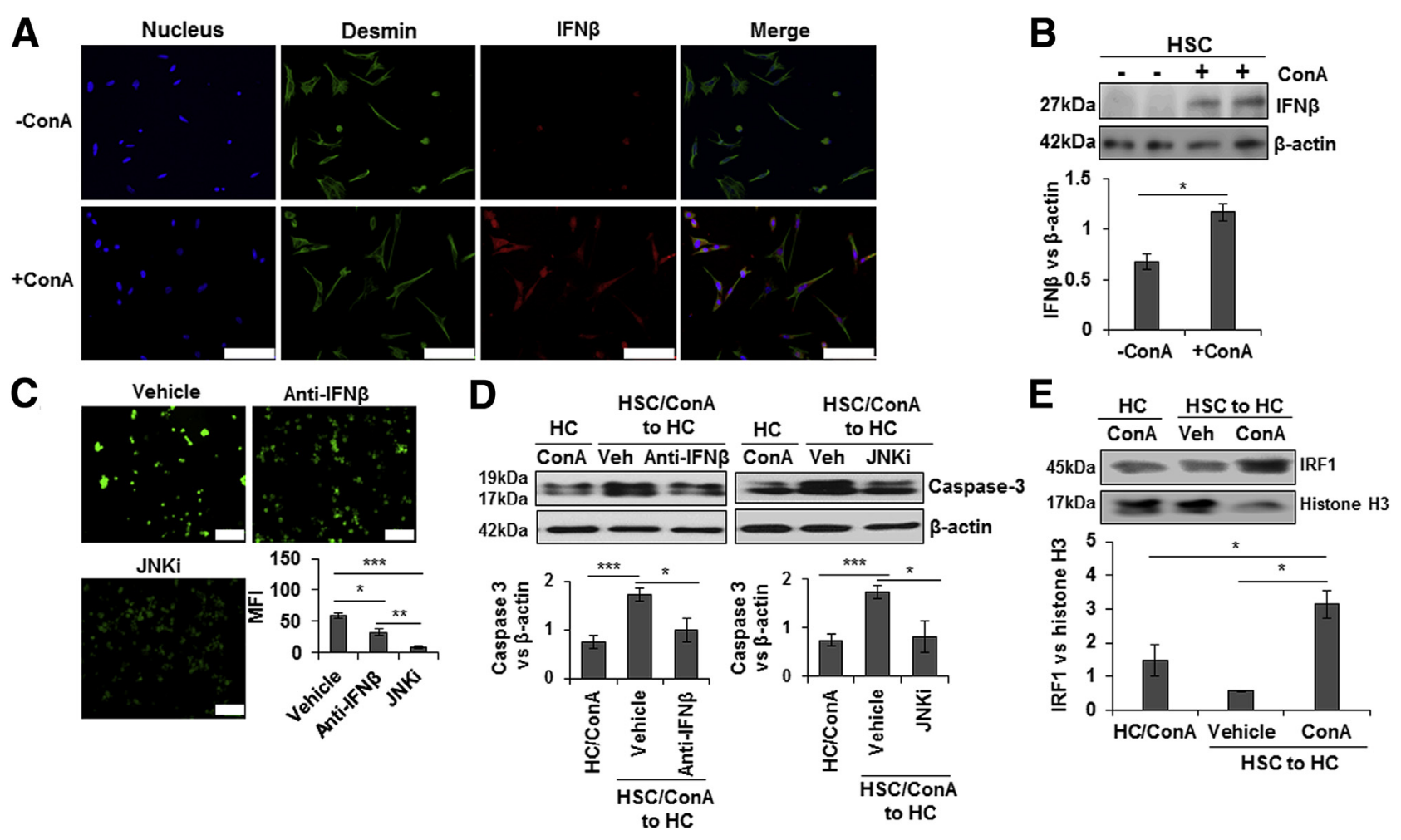

Figure 5 ConA/HSC-induced hepatocyte injury is ameliorated by anti-IFN- $\beta$ Ab and JNK inhibitor. Immunofluorescence staining (A) and Western blot analysis (B) show increased intracellular accumulation of IFN- $\beta$ in ConA-treated HSCs. Bar graph shows relative densitometry values of IFN- $\beta$ normalized to internal control ( $\beta$-actin). C: HSCs were incubated for 8 hours in a medium containing $50 \mu \mathrm{g} / \mathrm{mL}$ ConA. Anti-IFN- $\beta$ Ab $(1 \mu \mathrm{g} / \mathrm{mL})$ or JNK inhibitor (JNKi) $(\mathrm{SP} 600125 ; 10 \mu \mathrm{g} / \mathrm{mL})$ was added to the medium before transfer to hepatocytes. After 12 hours of incubation, $2^{\prime}, 7^{\prime}$-dichlorofluorescin diacetate staining was performed to determine oxidative stress. Bar graph shows mean fluorescence intensity (MFI). D: Protein lysates from hepatocytes incubated in ConA/HSC medium without or with anti-IFN- $\beta$ Ab or SP600125 were subjected to Western blot analysis to detect cleaved caspase-3. Bar graph shows relative densitometric values of caspase- 3 normalized to $\beta$-actin. E: HSCs were incubated for 8 hours in a medium containing $50 \mu \mathrm{g} / \mathrm{mL}$ ConA; medium was transferred to hepatocytes. After 12 hours of incubation, nuclear translocation of IRF1 was determined. All images are representative of three separate experiments. Bar graphs show combined values from three independent experiments. Data are expressed as means $\pm \mathrm{SD}(\mathbf{B}-\mathbf{E})$. ${ }^{*} P<0.05,{ }^{* *} P<0.01$, and ${ }^{* * *} P<0.001$. Scale bar $=100 \mu \mathrm{m}(\mathbf{A}$ and $\mathbf{C})$. Veh, vehicle.

indicate that HSCs may be critical to the NKT cell component of liver injury, as evident from unaltered hepatic expression of natural killer group 2D receptor in WT mice, but its decreased expression in HSC-depleted mice after ConA treatment. We also found that the number of $\mathrm{CD} 4{ }^{+} \mathrm{T}$ cells increased in ConA-treated HSC-sufficient but not in HSC-depleted mice. These findings are consistent with hepatic recruitment of $\mathrm{CD} 4^{+} \mathrm{T}$ cells by HSCs on lipopolysaccharide challenge ${ }^{13}$ or I/R injury. ${ }^{42}$ In addition, we found a significantly reduced hepatic concentration of CXCL1 and decreased neutrophil infiltration in ConAtreated HSC-depleted than in HSC-sufficient mice. In this regard, hepatic mRNA and protein levels of TNF- $\alpha$ and IFN- $\gamma$, which are implicated in ConA-induced liver injury, ${ }^{16-18,43,44}$ were strongly increased in HSC-sufficient but only modestly in HSC-depleted mice. Furthermore, chemokines that recruit neutrophils and T cells (CXCL1 and CXCL10) also increased in HSC-sufficient but not in HSC-depleted mice after ConA treatment. Together, these data suggest that HSCs are critical to recruitment and retention of inflammatory and immune cells that contribute to the liver damage.
An important finding of our study is markedly increased IFN- $\beta$ expression, and the expression and nuclear translocation of IRF1 in ConA-treated HSC-sufficient as compared with the HSC-depleted mice. Previously, IRF1$\mathrm{KO}$ mice were found to be resistant to ConA-induced liver damage, in association with lower circulating TNF- $\alpha$ and IFN- $\gamma$ levels and their hepatic and splenic mRNA expression. ${ }^{35}$ Although IFN- $\gamma$ was suggested to induce nuclear translocation of IRF1 in hepatocytes on ConA administration, ${ }^{43,45}$ our data indicate that IFN- $\beta$ is also a powerful cytokine responsible for ConA-induced liver damage through IRF1. In fact, we recently found that lipopolysaccharide treatment of rats increases IRF1 and IFN- $\beta$ expression, and the IRF1-IFN- $\beta$ axis is critical to inducing autophagy and apoptosis in hepatocytes. ${ }^{9}$ Increased nuclear IRF1 in ConA/HSC-treated hepatocytes and inhibition of ConA/HSC-induced apoptosis of hepatocytes by anti-IFN- $\beta$ Ab as well as protection of IRF1KO mice from ConA injury in conjunction with lower hepatic IFN- $\beta$ support the contention about the IFN- $\beta /$ IRF 1 axis as a major pathway leading to hepatocyte damage. 

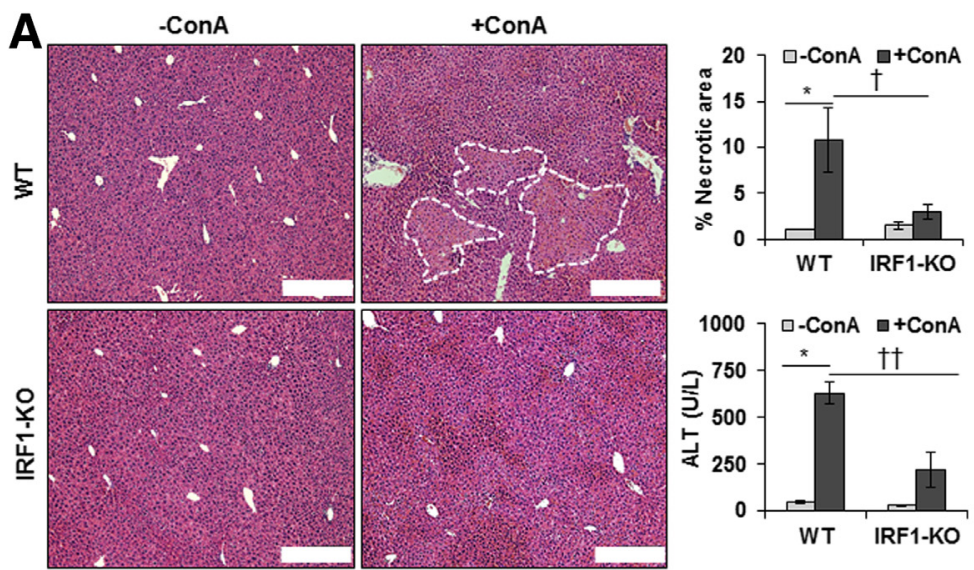

Figure 6 ConA-induced hepatic injury in IRF1-deficient mice. WT and IRF1-deficient mice were administered 20 $\mathrm{mg} / \mathrm{kg}$ ConA. Mice were euthanized at 6 hours, and liver injury and protein concentration of cytokines were determined. A: Hematoxylin and eosin-stained liver sections show robust inflammation and necrosis (dashed lines) in ConA-treated WT mice. Inflammation is strongly reduced in the IRF1-deficient mice. B: ConA-treated IRF1-deficient mice have significantly lower TNF- $\alpha$, IFN- $\gamma$, IFN- $\beta$, CXCL1, and CXCL10 as compared with the WT mice. Data are expressed as means \pm SD. $n=3$ to 6 per group. ${ }^{*} P<0.05$ versus control; ${ }^{\dagger} P<0.05,{ }^{\dagger \dagger} P<0.01$, and ${ }^{\dagger \dagger \dagger} P<0.001$ versus IRF1-K0 mice. Scale bar $=200 \mu \mathrm{m}(\mathbf{A})$. ALT, alanine aminotransferase.
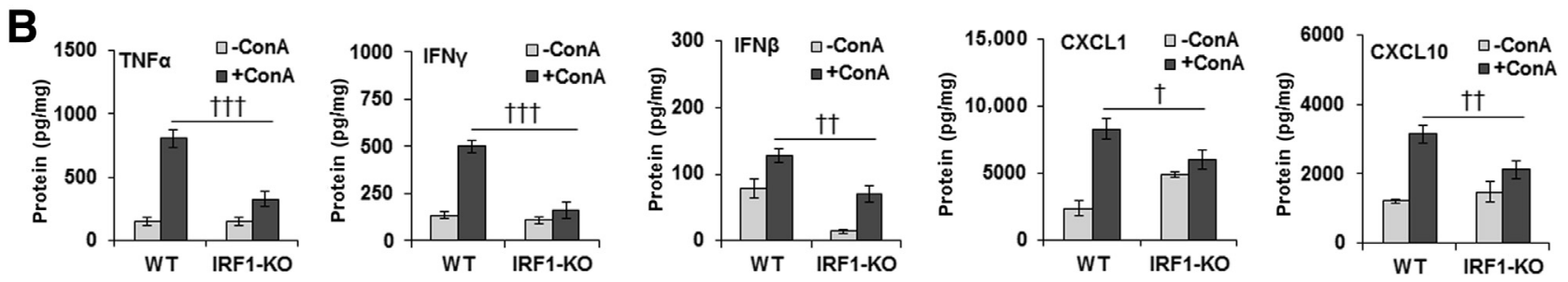

The other important role of IRF1 appears to be the regulation of the expression of cytokines by HSCs. Relatively much increased expression of TNF- $\alpha$, IFN- $\beta$, CXCL1, and CXCL10, which are all produced by HSCs, in HSC-sufficient but not in HSC-depleted or IRF1-KO mice indicated a direct effect of ConA on their expression in HSCs via IRF1. This proposal is supported by ConAinduced IRF1 expression and the expression of these cytokines/chemokines in isolated HSCs. ConA induced only a twofold increase in IRF1 expression in HSCs, whereas in vivo treatment resulted in nearly a 20 -fold increase. This difference is because of the fact that hepatocytes constitute the bulk of the liver cells. Also, nuclear IRF1 is associated with hepatocyte death that, in HSCs, is coupled to the expression/release of cytokines/chemokines. Although several other cell types (eg, T cells and macrophages/KCs) also produce cytokines/chemokines, their strongly reduced expression in HSC-depleted mice suggests that HSCs are critical to the overall inflammatory response. Indeed, augmented ConA-induced expression of the cytokines/chemokines by HSC-NPC co-culture compared with that by NPCs alone indicates critical bidirectional interactions.

Our in vitro experiments provided unequivocal evidence for a direct role of HSCs in ConA-induced hepatocyte injury. Media conditioned by ConA-stimulated HSCs induced oxidative stress and DNA damage in hepatocytes, and their apoptosis. ConA alone did not elicit such a response in hepatocytes, confirming that the effect is due to HSC-released mediators. Because ConA/HSC-induced hepatocyte apoptosis was inhibited by blocking JNK activation and by neutralizing IFN- $\beta \mathrm{Ab}$, it is apparent that HSC-released IFN- $\beta$ is a major mediator of hepatocyte injury. The direct role of HSCs was further confirmed by increased nuclear translocation of IRF1 in HSC/ConAtreated hepatocytes. However, unlike in vivo, no necrosis of ConA/HSC-treated hepatocytes was observed. Interestingly, unlike in hepatocytes incubated in ConA/HSC medium in vitro, caspase-3 activation was not apparent in the liver of ConA-treated HSC-sufficient mice. These data agree with an earlier report showing caspase-3-independent hepatocyte necrosis as the predominant mechanism of ConAinduced liver damage in vivo. ${ }^{39}$ Although several TUNELpositive hepatocytes found in ConA-treated mice might suggest involvement of other caspases, as significant inhibition of ConA-induced apoptosis was observed by blocker of caspase-1-like protease YVADcmk, ${ }^{46}$ a recent report by $\mathrm{Ni}$ et $\mathrm{al}^{47}$ demonstrated that TUNEL-positive cells could be either apoptotic or necrotic. Because ConA-treated HSCs induced apoptosis but not necrosis in vitro (Figure 5 and Supplemental Figure S8), it is conceivable that the caspase cascade is activated earlier after ConA challenge in vivo, and with increased generation of mediators of cell damage by infiltrating cells and ATP depletion, necrosis predominates as a major mechanism of cell death. ${ }^{47,48}$

The novelty of our findings is the direct response of HSCs to ConA in vitro, with the release of IFN- $\beta$ that consequently induces apoptosis of hepatocytes by stimulating IRF1 signaling. Furthermore, reduced inflammatory and immune cells, and significantly lower hepatic production of inflammatory mediators in ConA-challenged HSC-depleted mice than in HSC-sufficient mice, indicate that HSCs also orchestrate necrotic injury by recruiting and regulating the responses of other cell types to ConA. Our findings are distinct from a recent report, ${ }^{49}$ describing that prostaglandin D2 produced by KCs stimulates HSCs via the DP1 receptor and this interaction dampens the ConA-induced liver injury. 
Although the authors did not measure prostaglandin D2 in ConA-challenged mice per se, DP1 $1^{-1-}$ mice were found to be protected. However, a previous study reported DP1 expression by $\mathrm{KCs}$ and endothelial cells, albeit at somewhat lower magnitude than HSCs. ${ }^{50}$ We note that in the model we established, approximately $70 \%$ to $75 \%$ depletion of HSCs occurs. ${ }^{10}$ Considering the strong heterogeneity in the HSC population, ${ }^{51}$ the possibility that the residual HSCs exert a protective effect ${ }^{49}$ in the liver cannot be ruled out, and this should be a topic of future investigation.

\section{Supplemental Data}

Supplemental material for this article can be found at http://dx.doi.org/10.1016/j.ajpath.2017.05.015.

\section{References}

1. Lee WM: Acute liver failure in the United States. Semin Liver Dis 2003, 23:217-226

2. Takikawa Y, Endo R, Suzuki K, Tsubouchi H; Fulminant Hepatitis Study Group of Japan: Early prediction of short-term development of hepatic encephalopathy in patients with acute liver disease unrelated to paracetamol: a prospective study in Japan. J Hepatol 2009, 51: 1021-1029

3. Craig DGN, Lee A, Hayes PC, Simpson KJ: The current management of acute liver failure. Aliment Pharmacol Ther 2010, 31:345-358

4. Gandhi CR: Stellate cells in regulation of hepatocyte survival and function. Stellate Cells in Health and Disease. Edited by Gandhi CR, Pinzani M. San Diego, CA: Elsevier Press, 2015. pp. 209-225

5. Gandhi CR, Uemura T, Kuddus RH: Endotoxin causes up-regulation of endothelin receptors in cultured hepatic stellate cells via nitric oxide-dependent and -independent mechanisms. $\mathrm{Br} \mathrm{J}$ Pharmacol 2000, 131:319-327

6. Uemura T, Gandhi CR: Inhibition of DNA synthesis in cultured hepatocytes by endotoxin-conditioned medium of activated stellate cells is transforming growth factor- $\beta$ - and nitric oxide-independent. Br J Pharmacol 2001, 133:1125-1133

7. Thirunavukkarasu C, Uemura T, Wang LF, Watkins S, Gandhi CR Normal rat hepatic stellate cells respond to endotoxin in LBPindependent manner to produce inhibitor(s) of DNA synthesis in hepatocytes. J Cell Physiol 2005, 204:654-665

8. Thirunavukkarasu C, Watkins S, Gandhi CR: Mechanisms of endotoxin-induced nitric oxide, interleukin-6 and tumor necrosis factor-a production in activated rat hepatic stellate cells: role of p38MAPK. Hepatology 2006, 44:389-398

9. Dangi A, Huang C, Tandon A, Stolz D, Wu T, Gandhi CR: Endotoxin-stimulated rat hepatic stellate cells induce autophagy in hepatocytes as a survival mechanism. J Cell Physiol 2016, 231:94-105

10. Stewart R, Dangi A, Huang C, Murase N, Kimura S, Stolz DB, Wilson GC, Lentsch AB, Gandhi CR: A novel mouse model of depletion of stellate cells clarifies their role in ischemia/reperfusionand endotoxin-induced acute liver injury. J Hepatol 2014, 60: 298-305

11. Harvey SAK, Dangi A, Tandon A, Gandhi CR: The transcriptomic response of rat hepatic stellate cells to endotoxin: implications for hepatic inflammation and immune regulation. PLoS One 2013, 8: e82159

12. Marra F, Caligiuri A: Cytokine production and signaling in stellate cells. Stellate Cells in Health and Disease. Edited by Gandhi CR, Pinzani M. San Diego, CA: Elsevier Press, 2015. pp. 63-86

13. Dangi A, Sumpter T, Kimura S, Stolz DB, Murase N, Raimondi G, Vodovotz Y, Huang C, Thomson AW, Gandhi CR: Selective expansion of allogeneic regulatory $\mathrm{T}$ cells by hepatic stellate cells: role of endotoxin and implications for allograft tolerance. J Immunol 2012, 188:3667-3677

14. Sumpter T, Dangi A, Matta B, Huang C, Stolz D, Vodovotz Y, Thomson AW, Gandhi CR: Hepatic stellate cells undermine the allostimulatory function of liver myeloid dendritic cells via STAT3dependent induction of IDO. J Immunol 2012, 189:3848-3858

15. Gandhi CR: Stellate cells in hepatic immunological tolerance. Stellate Cells in Health and Disease. Edited by Gandhi CR, Pinzani M. San Diego, CA: Elsevier Press, 2015. pp. 227-249

16. Tiegs G, Hentschel J, Wendel A: A T cell-dependent experimental liver injury in mice inducible by concanavalin A. J Clin Invest 1992, 90:196-203

17. Tiegs G: Cellular and cytokine-mediated mechanisms of inflammation and its modulation in immune-mediated liver injury. Z Gastroenterol 2007, 45:63-70

18. Gantner F, Leist M, Lohse AW, Germann PG, Tiegs G: Concanavalin A-induced T-cell-mediated hepatic injury in mice: the role of tumor necrosis factor. Hepatology 1995, 21:190-198

19. Tandon A, Dangi A, Kumar S, Gandhi CR: Depletion of hepatic stellate cells abrogates Concanavalin A-induced liver injury [abstract]. Hepatology 2014, 60(Suppl S1):P223A

20. Committee for the Update of the Guide for the Care and Use of Laboratory Animals; National Research Council: Guide for the Care and Use of Laboratory Animals. ed 8. Washington, DC, National Academies Press, 2011

21. Bush TG, Savidge TC, Freeman TC, Cox HJ, Campbell EA, Mucke L, Johnson MH, Sovroniew MV: Fulminant jejuno-ileitis following ablation of enteric glia in adult transgenic mice. Cell 1998, 93:189-201

22. Kumar S, Wang J, Rani S, Gandhi CR: Hepatic deficiency of augmenter of liver regeneration exacerbates alcohol-induced liver injury and promotes fibrosis in mice. PLoS One 2016, 11:e0147864

23. Petrasek J, Iracheta-Vellve A, Saha B, Satishchandran A, Kodys K, Fitzgerald KA, Kurt-Jones EA, Szabo G: Metabolic danger signals, uric acid and ATP, mediate inflammatory cross-talk between hepatocytes and immune cells in alcoholic liver disease. J Immunol 2015, 98:249-256

24. Yang L, Jung Y, Omenetti A, Witek RP, Choi S, Vandongen HM, Huang J, Alpini GD, Diehl AM: Fate-mapping evidence that hepatic stellate cells are epithelial progenitors in adult mouse livers. Stem Cells 2008, 26:2104-2113

25. Mederacke I, Hsu CC, Troeger JS, Huebener P, Mu X, Dapito DH, Pradere JP, Schwabe RF: Fate tracing reveals hepatic stellate cells as dominant contributors to liver fibrosis independent of its aetiology. Nat Commun 2013, 4:2823

26. Bonder CS, Ajuebor MN, Zbytnuik LD, Kubes P, Swain MG: Essential role for neutrophil recruitment to the liver in concanavalin A-induced hepatitis. J Immunol 2004, 172:45-53

27. Hatada S, Ohta T, Shiratsuchi Y, Hatano M, Kobayashi Y: A novel accessory role of neutrophils in concanavalin A-induced hepatitis. Cell Immunol 2005, 233:23-29

28. Zhai Y, Qiao B, Gao F, Shen X, Vardanian A, Busuttil RW, KupiecWeglinski JW: Type I, but not type II, interferon is critical in liver injury induced after ischemia and reperfusion. Hepatology 2008, 47: 199-206

29. Kim KH, Dhupar R, Ueki S, Cardinal J, Pan P, Cao Z, Cho SW, Murase N, Tsung A, Geller DA: Donor graft interferon regulatory factor-1 gene transfer worsens liver transplant ischemia/reperfusion injury. Surgery 2009, 146:181-189

30. Fontana RJ, Hayashi P, Bonkovsky HL, Kleiner DE, Kochhar S, Gu J, Ghabril M: Presentation and outcomes with clinically apparent interferon beta hepatotoxicity. Dig Dis Sci 2013, 58:1766-1775

31. Tamura S, Warabi Y, Matsubara S: Severe liver dysfunction possibly caused by the combination of interferon beta- $1 \mathrm{~b}$ therapy and melilot (sweet clover) supplement. J Clin Pharm Ther 2012, 37: $724-725$ 
32. Geller DA, Nguyen D, Shapiro RA, Nussler A, Di SM, Freeswick P, Wang SC, Tweardy DJ, Simmons RL, Billiar TR: Cytokine induction of interferon regulatory factor-1 in hepatocytes. Surgery 1993, 114: 235-242

33. Tsung A, Stang MT, Ikeda A, Critchlow ND, Izuishi K, Nakao A, Chan MH, Jeyabalan G, Yim JH, Geller DA: The transcription factor interferon regulatory factor-1 mediates liver damage during ischemiareperfusion injury. Am J Physiol Gastrointest Liver Physiol 2006, 290:G1261-G1268

34. Dhupar R, Klune JR, Evankovich J, Cardinal J, Zhang M, Ross M, Murase N, Geller DA, Billiar TR, Tsung A: Interferon regulatory factor-1 mediates acetylation and release of high mobility group box1 from hepatocytes during murine liver ischemia-reperfusion injury. Shock 2011, 35:293-301

35. Senaldi G, Shaklee CL, Gou J, Martin L, Boone T, Mak TW, Ulich TR: Protection against the mortality associated with disease models mediated by TNF and IFNg in mice lacking IFN regulatory factor-1. J Immunol 1999, 163:6820-6826

36. Klune JR, Dhupar R, Kimura S, Ueki S, Cardinal J, Nakao A, Nace G, Evankovich J, Murase N, Tsung A, Geller DA: Interferon regulatory factor-2 is protective against hepatic ischemia-reperfusion injury. Am J Physiol Gastrointest Liver Physiol 2012, 303:G666-G673

37. Castellaneta A, Yoshida O, Kimura S, Yokota S, Geller DA, Murase N, Thomson AW: Plasmacytoid dendritic cell-derived IFN- $\alpha$ promotes murine liver ischemia/reperfusion injury by induction of hepatocyte IRF-1. Hepatology 2014, 60:267-277

38. Gunawan BK, Liu ZX, Han D, Hanawa N, Gaarde WA, Kaplowitz N: c-Jun N-terminal kinase plays a major role in murine acetaminophen hepatotoxicity. Gastroenterology 2006, 131:165-178

39. Ni HM, Chen X, Ding WX, Schuchmann M, Yin XM: Differential roles of JNK in ConA/GalN and ConA-induced liver injury in mice. Am J Pathol 2008, 173:962-972

40. Geissmann F, Cameron TO, Sidobre S, Manlongat N, Kronenberg M, Briskin MJ, Dustin ML, Littman DR: Intravascular immune surveillance by CXCR6+ NKT cells patrolling liver sinusoids. PLoS Biol 2005, 3:e113

41. Takeda K, Hayakawa Y, Van Kaer L, Matsuda H, Yagita H, Okumura K: Critical contribution of liver natural killer T cells to a murine model of hepatitis. Proc Natl Acad Sci U S A 2000, 97: $5498-5503$
42. Reifart J, Rentsch M, Mende K, Coletti R, Sobocan M, Thasler WE, Khandoga A: Modulating CD4+ T cell migration in the postischemic liver: hepatic stellate cells as new therapeutic target? Transplantation 2015, 99:41-47

43. Hong F, Jaruga B, Kim WH, Radaeva S, El-Assal ON, Tian Z, Nguyen VA, Gao B: Opposing roles of STAT1 and STAT3 in T cell-mediated hepatitis: regulation by SOCS. J Clin Invest 2002, 110:1503-1513

44. Streetz K, Fregien B, Plumpe J, Korber K, Kubicka S, Sass G, Bischoff SC, Manns MP, Tiegs G, Trautwein C: Dissection of the intracellular pathways in hepatocytes suggests a role for Jun kinase and IFN regulatory factor-1 in Con A-induced liver failure. J Immunol 2001, 167:514-523

45. Jaruga B, Hong F, Kim WH, Gao B: IFN-gamma/STAT1 acts as a proinflammatory signal in $\mathrm{T}$ cell-mediated hepatitis via induction of multiple chemokines and adhesion molecules: a critical role of IRF-1. Am J Physiol Gastrointest Liver Physiol 2004, 287: G1044-G1052

46. Künstle G, Hentze H, Germann PG, Tiegs G, Meergans T, Wendel A: Concanavalin A hepatotoxicity in mice: tumor necrosis factormediated organ failure independent of caspase-3-like protease activation. Hepatology 1999, 30:1241-1251

47. Ni HM, McGill MR, Chao X, Woolbright BL, Jaeschke H, Ding WX: Caspase inhibition prevents tumor necrosis factor- $\alpha$-induced apoptosis and promotes necrotic cell death in mouse hepatocytes in vivo and in vitro. Am J Pathol 2016, 186:2623-2636

48. Leist M, Gantner F, Bohlinger I, Tiegs G, Germann PG, Wendel A: Tumor necrosis factor-induced hepatocyte apoptosis precedes liver failure in experimental murine shock models. Am J Pathol 1995, 146: $1220-1234$

49. Fujita T, Soontrapa K, Ito Y, Iwaisako K, Moniaga CS, Asagiri M, Majima M, Narumiya S: Hepatic stellate cells relay inflammation signaling from sinusoids to parenchyma in mouse models of immunemediated hepatitis. Hepatology 2016, 63:1325-1339

50. Fennekohl A, Schieferdecker HL, Jungermann K, Püschel GP: Differential expression of prostanoid receptors in hepatocytes, Kupffer cells, sinusoidal endothelial cells and stellate cells of rat liver. J Hepatol 1999, 30:38-47

51. Geerts A: History, heterogeneity, developmental biology, and functions of quiescent hepatic stellate cells. Semin Liver Dis 2001, 21 $311-335$ 